\title{
Towards a dialogic theory of how children learn to think.
}

Rupert Wegerif, Graduate School of Education, University of Exeter, UK. R.b.wegerif@exeter.ac.uk

Pre-print draft of paper in press for Thinking Skills and Creativity, 2011

\section{http://dx.doi.org/10.1016/j.tsc.2011.08.002}

Relevant keywords: dialogic, creativity, knowledge construction, Heidegger, Bakhtin, Levinas, ontology, theory, thinking, cognitive development

\begin{abstract}
This paper develops a dialogic theory of thinking and of learning to think that has implications for education. The theory is offered as a contrast to theories that are based on both Piaget and Vygotsky. The paper proceeds by unpacking and interweaving three key concepts: dialogue, thinking and learning in order to argue that learning to think can be understood as a shift in self-identification towards becoming dialogue. This theory is then applied to the context of primary classrooms through the analysis of three short episodes of interaction. These analyses offer evidence that a dialogic theory of learning to think can offer new and valuable insights into classroom interaction with the potential to inform pedagogy.
\end{abstract}

Key words: Bakhtin; dialogic; thinking; learning theory; social interaction 


\section{Introduction}

In the centenary conference of the birth of both Piaget and Vygotsky held in Geneva in 1996 Jerome Bruner gave a keynote in which he claimed that research into how children learn to think could all be located on a continuum with Piaget on one end and Vygotsky on the other (Bruner, 1996). In 2011, some 15 years later, this still seems to be the case with many articles on how children learn to think tracing their intellectual sources either to Piaget or Vygotsky. At the same time the assumption apparently shared by both Piaget and Vygotsky, that the development of thinking could be adequately described in terms of essentially mathematical or logical structures and procedures, has recently been heavily challenged by neuro-science research (e.g Damasio, 1994: see Wertsch, 1996 and Wegerif, 1999; 2011, for a more detailed account of the rationalist assumptions shared by Piaget and Vygotsky). As Shaun Gallagher brings out in a recent paper, the latest cognitive development and neuroscience research indicates not only that infants learn to think in the context of relationship and interaction but also that their thinking is an aspect of those relationships and interactions and cannot easily be abstracted from them (Gallagher, S. in press). In the light of these developments we need a new and different way of conceptualizing thinking and what it means to learn how to think. In this paper I sketch out a dialogic theory of learning to think which offers a radical alternative to both neo-Piagetian and neo-Vygotskian theories because it is entirely described in terms of the quality of relationships without reference to 'cognitive structures'. I progress the argument through a conceptual analysis of three key terms: dialogue, thinking and learning. I then illustrate the potential value of this theory for understanding how children learn to think with analyses of episodes of classroom interactions.

\section{Part 1: the argument}

\section{Question 1: What is a dialogue?}

Below I unpack the concept of dialogue, outlining 6 key features of a dialogic approach to education.

\section{1) Dialogic as the experience of being on the inside of dialogues}

When we think of dialogues we probably think of empirical dialogues that occur at a certain place and time between particular people. In doing this we are looking at dialogues as if from the outside. But dialogues also have an inside. On the inside of the dialogue we might be talking about people who are not present, distant places and past or future events. From the 
outside dialogues are always situated in space and time but when lived from the inside dialogues establish their own space and time. This is what distinguishes a dialogue from an interaction. Robots can interact but their interactions remains in external space. When humans enter into dialogue there is a new space of meaning that opens up between them and includes them within it.

The distinction between taking an external view of dialogues and an internal view is so obviously a part of human experience that it hardly needs justification. It is at the heart of all theories that could be called dialogic. Socrates, for example, distinguishes between living words that are carried on the warm breath of relationships and the dead words of written accounts that are like seeds left on flagstones in the sun (Plato, 2006). This distinction is picked up by Paul in the New Testament in the resonant phrase 'the letter kills but the spirit brings life' (New Testament, 2 Cor 3:6) and is clear in Buber's distinction between the attitude of objectification, 'Ich-Es' ( 'I-it' ) to the attitude of dialogue 'Ich-Du' ('I-thou') (Buber, 1958). The external 'objective' view that locates things in their proper place is 'monologic' because it assumes a single true perspective. The internal view that takes the other seriously is 'dialogic' because from this perspective meaning always assumes at least two perspectives at once so it is reason through and across difference ('dia' from the Greek is mostly translated as 'through or across' so 'dialogic' could be translated as something like 'logic across difference' or perhaps as meaning emerging from the interplay of different perspectives).

\section{2) Dialogic Space}

I first found the term Dialogic Space useful when trying to answer the question why some groups of children were more successful in solving reasoning test problems than others. The more successful groups seemed to be listening to each other, asking each other for help and changing their minds as a result of seeing the problem as if through the eyes of the others. In less successful groups children related to each other differently either competing as individuals to see who could get the right answer or not challenging or criticising each other in order to maintain group solidarity.

The term 'space' here is a metaphor and metaphors can be misleading. It could equally be called 'Dialogic Time' or, in Bakhtin's term, a 'chronotope' (i.e a 'space-time') and is similar to Bakhtin's notion of 'Great Time' which he proposes as the 'space' of dialogue between the voices of all times and places explaining why he, a $20^{\text {th }}$ Century Russian 
could fruitfully engage in dialogue with voices from ancient Greece (Bakhtin, 1986 p170). The metaphor of 'space' here is not so much from physical space as described by Aristotle and Euclid but from the use of the term 'space' to refer to any multidimensional map or graph, like the idea of a 'Search Space' in computing which is the set of all possible solutions for a search, the idea of a Hilbert Space in mathematics or the widely used idea of a Design Space, which maps the many dimensions required for the design of any given artifact (Boden, 1990; Sharples, 1999). The main difference between Dialogic Space and these other kinds of spaces, is that each position in a Problem Space, Hilbert Space or a Design can be completely specified. The specification of the exact meaning of each position in a dialogue depends on succeeding utterances and so can never be closed down (Bakhtin, 1986, 171). In other words 'Dialogic Space' is more of a dynamic continuous emergence of meaning than a static 'space'. Perhaps the term space is misleading and the single term 'eventing' might be more apposite (Badiou, 1988) but the metaphor of space allows us to speak of the opening, closing, widening and deepening a space all of which moves prove to be useful in the classroom.

\section{3) Inside-outness outside-inness of dialogic}

One important defining feature of a dialogue is the presence of the other on the inside of the formation of my utterances even before I open my mouth to speak. If my son Danny and I are playing with Lego and he shows me a Roman catapult he has made and I say: 'That is pretty cool, but I think it needs something: let's try putting a bar here to stop the arm going too far.' You might think it is obvious that my utterance starts with me saying, 'That is pretty cool,' but even as I framed that utterance Danny was there on the inside because I was speaking to him. The words 'That is pretty cool' came quite naturally but I would probably not use these same words if my boss, Sir Steve Smith, the ViceChancellor of Exeter University, showed me his latest report on how the university is going to reach its research income targets. In other words I naturally use Danny's vocabulary and style because I am responding to him. In any dialogue the person you are speaking to, the 'addressee', is always already there at the beginning of the utterance just as you are there already on the inside when they frame their reply to you. In any dialogue we do not just address ourselves to the other as a physical object but we address a projected image of them, which includes our idea of how they are likely to respond to what we are saying (Rommetveit, 1992; Linell 2009). 
This inside-out and outside-in nature of dialogues explains why education is possible at all. Bakhtin points out that there is a difference between an authoritative voice and a persuasive voice. The authoritative voice remains outside of me and orders me to do something in a way that forces me to accept or reject it without engaging with it whereas the words of the persuasive voice enter into the realm of my own words and change them from within (Bakhtin, 1981 p343). Education, as opposed to training or dressage, always requires this persuasive or dialogic voice that speaks to the student from the inside. The addressee enters into the very beginning of an utterance and how in a true dialogue it is no longer possible to say who is thinking (Merleau-Ponty, 1968, p15 and 113: Merleau-Ponty,1964, p29 and p159).

\section{4) The 'situation' of dialogue}

The socio-cultural movement in psychology has been defined through treating human behaviour as situated both culturally and historically (Rogoff, Gauvain and Ellis, 1991). At first glance dialogic theory fits into this situated view easily as meanings are not universal but are situated within dialogues. How we interpret the meaning of any utterance, included theories, must depend upon the dialogue in which such utterances are located including the utterances they respond to and the utterances they might seek to influence in the future (Linell, 2009). However not all dialogues are between physically embodied voices. Even when the 'other' I address appears to be a physical person standing in front of me I may well be addressing a cultural voice. For example if I am talking to you about the role of research and you use key words that I associate with an Enlightenment view of progress through reason then I might find myself engaged in dialogue with that cultural voice while apparently engaged in dialogue with you, a concrete person. When Bakhtin writes of voices in dialogue as 'embodied' he often means embodied in texts or coming out of and reflecting social and historical movements and experiences, he does not normally mean that voices are embodied in just one physical human being. Indeed his concept of 'heteroglossia' suggest that it is not possible for words to have simple, single and located meanings as they always carry with them echoes of all the other voices that have used the same words before in different ways.

There is another more serious problem for the idea that dialogues are situated. As well as having perhaps a physically situated addressee and cultural voices, utterances in dialogues also always address a 'super-addressee' (Bakhtin, 1986, p126-7). This superaddressee is described by Bakhtin as the 'witness' or 'third' that is an inevitable part of any dialogue. 
Bakhtin does not spell this out but the 'third' addressee in a dialogue is inevitably present in all dialogues simply because I can hear myself speaking. When I talk and hear my own words it is as if I am another person listening to them and then I naturally assume the position of a witness or 'third'. Bakhtin makes the point that, as well as seeking to persuade you, my immediate addressee, I also seek to engage in dialogue with an ideal listener who could make sense of what I am saying even if you cannot. I think this could be seen as stemming from a projection of the self as another who listens to the words of the self but can understand and judge them as if from an outside position. He points out that in different times this superaddressee is imagined differently, sometimes being God and sometimes 'the future community of scientists' but in every age there is such an ideal as it is an essential part of the nature of dialogue. This elaborated cultural image of the superaddressee is an extension, I would argue, of the witness position in every dialogue that comes from listening to myself speaking as if I was other to myself.

Dialogues have two sides. Viewed from the outside they are situated in space and time, culture and history. Viewed from the inside they can invoke any time and any space and seek to engage in dialogue with the unsituated outside perspective of the superaddressee. It is true to say that for dialogic theory any particular conception of the superaddressee is in fact always culturally and historically situated. However the superaddressee is a universal feature of dialogue stemming from the very simple and inescapably real experience of listening to my own voice as I speak. It is this mechanism internal to dialogues, which means that dialogues are never fully situated on the inside but can seem to escape their situation.

It is only within dialogues that people come to define and know their situations and interpret them. If situation in space, time, culture and history is always constructed within Dialogic Space then it follows that Dialogic Space, is, in its essence, not so situated. Dialogic Space is, in a sense, the situation of situation. However, this is not the whole story. The true 'situation' of situation is more paradoxical. The situated outsides of dialogues and the potentially unsituated insides of dialogues are always bound up together. There is a mutual envelopment between these two perspectives by which I mean to say that meanings within dialogues are always within cultural and historical situations but at the same time cultural and historical situations are always interpreted and given meaning from within dialogues. The idea that the dialogic relationship is one of mutual envelopment between insides and outsides around a gap is articulated by Merleau-Ponty as a relationship he calls the Chiasm (1964; 1968). 


\section{5) The dialogic gap}

Volosinov, Bakhtin's close collaborator in the 1920's, famously wrote that "meaning is like an electric spark that occurs only when two different terminals are hooked together", and further that: "In essence meaning belongs to a word in its position between speakers; that is, meaning is realised only in the process of active, responsive, understanding." (Volosinov, 1986 p102). Bakhtin repeats this same point even more simply when he writes that meaning does not exist in a vacuum but is always a response to a question (Bakhtin, 1986, p168). These meanings that arise within relationships as answers to questions include every kind of 'thing' or 'identity' including 'self' and 'other'. Understanding the everyday phenomenon of dialogue therefore pushes us towards an unusual way of thinking: a way of thinking that takes difference seriously.

It is common to think of reasoning as trying to reach agreement. Leibniz, for example, refers to reducing different perspectives to identity (Leibniz, 1973, p 205) and this tradition is carried forward in some contemporary communication theory where the need for achieving 'common ground' is emphasized (e.g Clark and Brennan, 1991). However, Bakhtin points out that if we were to reach agreement to the extent that our positions coincided then there would be no more flow of meaning. Meaning depends on seeing from more than one point of view at once. If we could not see something as if it could be other than it is then we could not be aware of it at all. To see a thing only as it is without the possibility of it being different from what it is would be the kind of monologic vision that a video-camera has, that is to say perception with no meaning. To be conscious is to see as if through the eyes of another as well as through one's own eyes. The difference between self and other or, as I prefer to see it, an inside perspective and an outside perspective, is a necessary condition for meaning. Dialogic Space therefore requires and presupposes a dialogic gap between irreducibly different perspectives held together in a relationship of proximity. But in fact the dialogue always continues. People always have irreducibly different perspectives on the world because we have different bodies and histories. Even when we think that we agree about concepts we inevitably understand those concepts differently. This is not to suggest that achieving 'common ground' is not important in dialogues but that it is one moment in a larger flow of meaning that is more fundamentally described as the tension between different perspectives held together in proximity around a dialogic gap. If there is no gap then there is no dialogue and if there is no dialogue then there is no meaning. 


\section{Ontological status of Dialogic Space}

Dialogues in education are often discussed in terms of epistemology as a form of "shared inquiry' and a way of helping in the 'collaborative construction of knowledge' (Wells, 1999: Linell, 2009; Mercer, 1995). I propose that it is also useful to think of dialogues in terms of ontology, especially the ontology of Dialogic Space. By using the term ontology I am suggesting two things. First that the concept of Dialogic Space is not just an idea but is pointing to something real that can help us understand how we think and how children learn to think. Science tends to work by hypothesising underlying causal mechanisms and Dialogic Space is not different. Secondly, I am suggesting that the aim of education is not simply knowledge but ways of being. Dialogic is not simply a way for a subject to know about a world out there beyond the subject but it is also about a way of being in the world. Referring to an ontological interpretation of dialogic is another way of saying that dialogic education is education for dialogue as well as through dialogue in which dialogue is not only treated as a means to an end but also treated as an end in itself (see also Matusov, 2009, especially Chapter 1 and Sidorkin, 1999).

\section{Question 2: What is thinking?}

Heidegger, in 'Was heisst Denken?', an essay sometimes translated as 'What calls thinking?', begins with the claim: 'We come to know what it means to think when we ourselves are thinking. If our attempt is to be successful, we must be ready to learn thinking.' (Heidegger, 1978, p369) Thinking has to be learnt, he writes, but the first step in learning thinking must be to unlearn all the nonsense that has been taught about thinking. He writes, for example, that 'Science is not thinking'. He means here that algorithmic accounts of thinking (and of science) as facts, linked by logical arguments or as the application of a defined method are at best accounts of thinking made up after the event that tell us nothing about what thinking is really like. So what is thinking really like? Heidegger does not answer this question directly but he replaces it with another question: 'What calls us to think?' (Heidegger, 1978, p390). By doing this he is pointing out that while cognitive science has tended to describe thinking as if it was a process that we can control, like applying a set of tools to solve a problem, the actual experience is much more like being called to think by something beyond us. He writes, rather obviously perhaps, that what most calls us to think is that which we find most thought provoking. While we can never fully grasp hold of that which calls us to think, the very fact 
that we allow ourselves to be called by it means that our thinking becomes a kind of pointing towards it.

Levinas accepted Heidegger's claim that we are called out to think by something beyond us but this 'something' is not, he claimed, a mysterious abstraction like 'Being', as Heiddeger had perhaps implied. Thinking begins, Levinas claims, when we are called to explain ourselves in the face of real other people. From the very beginning, to be a self, for Levinas, is to be a kind of response to others who call us out: they call 'Are you there?' and the self says: 'Here I am' (Le mot Je signifie me voici, répondant de tout et de tous. Levinas, 1978, p180) It is in the context of a relationship of responsibility (a need to respond) binding us to other people that we are first called to think, in order to justify and explain ourselves to others.

Although Levinas writes a lot about concrete real other people, his account of thinking is similar in many ways to Heidegger's original account. He writes that there is something about other people that we can never grasp, their 'Infinite Otherness' from us, and it is this mysterious and ungraspable otherness of the other that is what most calls out to us. Levinas invokes this 'Infinite Other' in an ethical context but it can also be seen as an account of how we learn to think. The description of thinking as a kind of response to the call of Being for Heidegger become thinking as a response to the call of Infinite Otherness.

Some might say that Levinas's idea of the Infinite other seems just as vague and mystical as Heidegger's concept of Being. But actually it is quite a concrete and straightforward idea. It is simply another way of saying that I am in a relationship with you but any idea I form of you does not fully grasp you because you are more than my images of you. Cognition in general always occurs within the context of a prior relationship with otherness in general that cognition therefore cannot completely comprehend. In other words there is always an outside to our representations, that which we cannot grasp, and it is because of this that Levinas uses the term 'infinite' in the simple sense of 'not finite'. The encounter with the face of the concrete other, Levinas claims, is an encounter with this Infinite Other that outstrips our comprehension and yet calls us to respond.

Heidegger's and Levinas's accounts of thinking can be called dialogic not because they locate all thinking in real dialogues between specific individuals but because their accounts of thinking do not reduce it to 'structures' but assume a context of relationship. 


\section{1) The vertical dimension of thinking}

The idea of teaching thinking implies values and criteria for good thinking. Piaget, for example, has a clear account of the vertical dimension of the development of thinking from the more concrete and 'operational' towards the more abstract and universal. Vygotsky follows this vertical account of the development of thinking quite closely just questioning the internal mechanism of growth that Piaget proposed in order to give a greater role to culture and education (Van der Veer and Valsiner, 1991: Wegerif, 1999: Matusov, 2011). Can a more dialogic account of learning to think also offer an account of the vertical dimension of the development of thinking that is required by education?

One possible response to this question from a dialogic or more generally socio-cultural perspective might be that there are many different kinds of thinking for different purposes in different contexts and so it is not possible to talk about teaching 'good thinking' because there is no abstract 'thinking in general' (e.g Rogoff et al, 1991). This is the implication of a situated 'communities of practice' approach to learning (Lave and Wenger, 1991). I have responded to this possible criticism of the whole idea of teaching thinking elsewhere (Wegerif, 2004). Accounts of different contexts of thinking describe the horizontal dimension of thinking but in addition to this we need an account of the vertical dimension of thinking in order to understand thinking in response to a new event or thinking that cuts across contexts in order to criticise or challenge existing practices.

Bakhtin's notion of the 'witness' position or 'superaddressee' in every dialogue is relevant for re-constructing the vertical dimension of learning to think within a dialogic theoretical framework. In a dialogue we might start just trying to persuade the other person but in doing so we end up listening to our own arguments as if from an outside point of view. For example in analysing the talk of children in primary classrooms I often see children changing their minds in the face of questioning by other children not in fact because they tried to see the issue or problem from the point of view of the specific questioner but simply because they looked at it again as if afresh from the outside and realized that they had got it wrong. In this common move they are stepping back and looking again at their own utterances as if from the perspective of an outside witness.

As outlined above in the section on Dialogue, the superaddressee, although not a physically embodied perspective, serves as an influential voice or perspective in all dialogues. Bakhtin, 
distances himself from a 'spiritual' account of thinking which transcends its context, when he writes of the superaddressee:

The aforementioned third party is not any mystical or metaphysical being (although, given a certain understanding of the world, he can be expressed as such) - he is a constitutive aspect of the whole utterance, who, under deeper analysis, can be revealed in it. This follows from the nature of the word, which always wants to be heard, always seeks responsive understanding, and does not stop at immediate understanding but presses further and further (indefinitely). (Bakhtin, 1986, p126-7).

It follows from Bakthin's account of the superaddresee that if you try to pin down this position in order to dialogue with it you will find that another superaddressee position is automatically generated. Bakhtin did not bring this out but with the benefit of reading Bakhtin after reading Levinas we can see that the infinite regress implied by the idea of the superaddressee means that it leads to a more cognitive version of the Infinite Other. While within a specific culture the superaddressee might take on a particular form which we dialogue with, shall we say an image of God, then there will also be a witness or superaddressee position generated by this dialogue. In other words if one is open in a dialogue and listens closely there is no final position but always a voice from outside the consensus with a new perspective asking to be heard. This takes us in the direction of Levinas's Infinite Other, that part of the otherness of the other that can never be contained or represented within my words but always outstrips my capacity to understand. But it must be emphasized that the cognitive Infinite Other invoked here is not any kind of static thing or image or person but simply the name given to an infinite process of questioning.

This analysis of the implicit infinity in dialogues enables us to understand more clearly how children learn to reason. First they are called to explain themselves in dialogues with specific others. In the act of explaining themselves they become drawn into a dialogue with a third position that every dialogue generates, the position of the super-addressee. This position can become blocked as a particular set of rules or criteria, those instantiated in a particular community of practice for example, or the children can be drawn further into relationship with the Infinite Other. This is where this account drawn together from a combination of Bakhtin and Levinas goes beyond the otherwise related account of George Herbert Mead. Mead offered a similar account of how children learn to think by being drawn out to see from the point of view of others and then the 'Generalised Other' who represented the norms of the 
community (Mead, 1934). The Generalized Other is certainly a superaddressee figure but if we engage in dialogue with the Generalized Other a new superaddressee position is generated which enables us to question these norms of the community and perhaps revise them. There are always voices outside of the community questioning the rules of good reasoning that the community upholds and listening to those voices with respect takes us in the direction of the Infinite Other.

\section{Question 3: What is learning?}

Lave and Wenger's situated account of learning as joining and becoming more central in a community of practice has been influential (Lave and Wenger, 1991). In relation to thinking it is misguided in so far as it implies that thinking is always limited by the criteria of good thinking found within communities (Lave and Wenger, 1991; Wenger, 1999). This is an ethically dangerous idea that is disproved every time we are challenged to think by a voice outside of our community. However there is one interesting implication of situated learning theory that I would like to borrow and build upon to understand dialogic education better, this is that learning should be understood as a trajectory of identity within a social context (Wenger 1999, p153). It has long been clear that learning anything significant changes who we are and how we make sense of the world around us. This idea is already found, for example, in Piaget's notion of accommodation. However whereas Piaget's and even Vygotsky's ideas of learning as the development of the self are abstract, Lave and Wenger situate this in a cultural context as becoming a self in a society.

\section{1) Identity and identification}

Identity sometimes refers to things that do not change much like being British or female or a teacher. However, there is also a more shifting ground of identifications, like the way in which we might identify with being one kind of person at an office party and then shift to identify with being a different kind of person at a family funeral. The way in which Wenger and other educationalists are increasingly using the term 'identity' to understand an important dimension of learning is not so much as a noun but as a verb. The interest here is in the active process of identification and why and how learners identify with different self-images at different times. This is well summed up in a recent article on identity in learning mathematics by Paul Cobb and colleagues:

We take as our starting point the colloquial meaning of identifying, namely, to associate or affiliate oneself closely with a person or group. Our concern is with both how students come to understand what it means to 
do mathematics as it is realized in their classroom and with whether and to what extent they come to identify with that activity (Cobb, Gresalfi and Hodge, 2009).

\section{2) The vertical in learning}

One problem with the learning as identification with social practices model however is that, on its own, it is all horizontal and lacks an adequate account of vertical learning. Learning as a trajectory of identity on Wenger's model can account for how one might learn to be a good citizen in a democratic society but it could equally account for how one might learn to be a good gang member. It is about how we get socialised into different group norms: it does not account for how we might learn to become more aware of our identifications in order to question and transform group norms.

Just as the notion of teaching thinking requires an account of what progress and development in thinking look like so, in a similar way, the idea of learning to think cannot be left as a neutral account of processes of socialisation but implies a notion of learning to think well. The dialogic account of learning to think as being drawn into dialogue with the Infinite Other that I have outlined offers the vertical dimension that is required for education and that is missing in Wenger's account and in situated learning theory in general.

\section{3) Identification with orientations in groups}

In a similar way to Paul Cobb's account quoted earlier, Neil Mercer and I found that shifting self identifications seemed crucial to understanding the different types of talk we found in small groups in classrooms. Disputational Talk, in which children try to defeat each other and be the winner, depends on an identification with a narrow and defended self-image where what is seen as 'self' is defined against others. This sort of identity can be found in the common phrases 'I win, you lose' or 'winner takes all'. People engaged in Disputational Talk are trying to beat each other, they are not trying to learn from each other. Cumulative Talk, by contrast, depends on all in the group identifying with the group identity more than with their individual identity. They do not want to challenge each other since that might disrupt the harmony of the group. In cumulative thinking there is no incentive to challenge ideas or explore reasoning, instead people seek to agree with each other to maintain the feeling of belonging to the group. We have videos of cumulative groups where different opinions were in fact expressed, almost by accident, but were then just ignored by everyone present in order to maintain the appearance of unity. 
As well as cumulative and disputational talk we found a third kind of talk that Neil Mercer followed Douglas Barnes in calling Exploratory Talk. Exploratory Talk involves engaging critically with each others' ideas within a shared relationship. The definitions of this by Barnes and then by Mercer invoke explicit reasoning (Mercer, 1995: Littleton and Mercer, 2007). However a experimental study led by Sylvia Rojas-Drummond in Mexico shows that teaching exploratory talk leads to improvements in collaborative creative or divergent tasks without any explicit reasoning (Rojas-Drummond et al, 2006). This finding implies that what is essential to 'Exploratory Talk' is not the explicit reasoning. Just as disputational talk and cummulative talk can best be defined by the type of identification they imply, so can the intersubjective reality referred to previously by the term exploratory talk. I now prefer the term dialogic talk since what seems to be most essential to this type of talk is identification with dialogue itself.

Identification with the 'space of dialogue' was an idea I put forward in 1997 writing with Neil Mercer to explain the trajectory of learning towards learning to think in small group talk (Wegerif and Mercer, 1997). It was meant as an answer to the question: from what standpoint are children able to challenge their own thinking? How is it possible for them to change their minds because of what they hear in a discussion? If they are thinking then they are not simply identifying with their initial position or their self-interest, nor are they simply identifying with the other speaker's position, although they may be listening carefully. If they are able to change their minds it must be because they are identifying in some way with the process of the dialogue itself and the ideal of truth that it generates.

\section{4) Combining identification with verticality}

Both disputational talk and cumulative talk involved identification with limited images, one an image of self and the other an image of the group. Dialogic talk however is characterized by openness and respect for difference. As described in the first section of this paper, dialogic is actually defined by a constitutive dialogic gap or difference. Disputational and Cummulative talk are at the same horizontal level, they are just different types of talk characterized by different identifications. Identifying with the non-identity of dialogue is at a different ontological level taking us in the direction of the vertical. This account of how group thinking improved in our studies suggests a general direction in the development of more effective thinking away from identification with limited entities or images, and towards 
identification with the open and non-identical space of dialogue. In a sense this ideal of identification with non-identity is an oxymoron but it is a productive oxymoron pointing us in the direction of a practice of reflection capable of dissolving fixed images and assumptions.

The earlier discussion of the third position in every dialogue and the progression from dialogue with specific others through dialogue with projected cultural voices and on to dialogue with the Infinite Other explains why identification with the space of dialogue leads to better thinking and measurably better problem solving in groups. Identification with Dialogic Space is functionally equivalent to identification with being in dialogue with the Infinite Other and could perhaps also be described as openness to the other and openness to the new.

\section{Part 2: Classroom illustrations of teaching and learning thinking}

So far I have developed a dialogic theory of learning thinking through overlapping explorations of the concepts of dialogue, thinking and learning. In this section I will illustrate how this theory can help us understand what we observe in classrooms where children are learning to think. I will take three short illustrations from the context of mathematics in three different primary schools with different groups of children.

\section{Example 1: Seeing a pattern in a picture}

I mentioned earlier the extensive empirical investigations I conducted with Neil Mercer and others including Lyn Dawes, Karen Littleton and Sylvia Rojas-Drummond into the impact of teaching Exploratory Talk. The experimental design used in a number of studies enabled us to compare successful talk in the context of solving reasoning test problems with unsuccessful talk. Comparative analysis of the successful and the unsuccessful talk of the same group of children working together on the same problems helped to reveal what aspect of the dialogue really made a difference. Various illustrations and extracts of this analysis have been published in different articles and book chapters with the general argument that they show that language can be used more effectively as a tool for thinking. In the first extract of talk, Elaine, John and Danny are talking about a Raven's problem before our intervention promoting exploratory talk. They did not get it right. In the second extract, from the test given three months later after they had completed all of the 'Thinking Together' lessons (Dawes, Mercer and Wegerif, 2004), they succeed in solving the same problem. The focus of my analysis is on why they succeed in solving the problem in the post-test condition when they failed in the pre-test condition. 


\section{Figure 1. Problem A}

Transcript extract 1: John, Elaine and Danny: Before talk lessons: Problem A.

Elaine: No, because it will come along like that (Elaine circles answer 5 )

Transcript extract 2: John, Elaine and Danny: After talk lessons: Problem A.

John: Number 5

Danny: I think it's number 2

John: No, it's out, that goes out look

Danny: Yeh but as it comes in it goes this

Elaine: Now we're talking about this bit so it can't be number 2 it's that one

Elaine: It's that one it's that one

Danny: Yeh 'cos look

Elaine: 4

Danny: I agree with 4 (John nods his assent and Elaine circles answer 4)

If you look just at the darker lines running vertically you might think that the answer is number five because that continues the pattern for these lines. This (false) conclusion is that which the children reached in their initial 'pre-test' attempt. Elaine did not pause to consider alternatives or to reach agreement with her group, but circled answer five. That she used the word 'because' reflects the fact that she was responding to someone else's suggestion, made through silent pointing at one of the pictures. In this pre-test condition there was little discussion. The children rushed through all the problems given without much talk. After the intervention programme consisting of a series of ten Talk Lessons, the three children took 
more time over the problem. As before, it seems that the pattern of the dark lines is noticed and John offers number five as the answer. But this answer is only made as a suggestion. Danny puts forward number two as the answer, apparently because he is looking at the horizontal pattern of the lighter lines. John explains (through a combination of words and pointing) that the vertical black lines have to 'go out'. Danny in turn explains that it cannot be number five because the light lines have to 'go in'. Each of the two boys has adopted a different perspective; John takes the side of the dark lines, Danny that of the light lines. Each can see enough to refute the position of the other but this does not produce the solution. Elaine then comes up with the answer which combines the dark lines going out with the light lines going in, that is number four. Once she has expressed this both Danny and John can see that she is right.

The perspectives pointed to by John and Danny, almost certainly help Elaine to leapfrog to a synthetic vision that takes their two points of view into account in offering a third. 'Tools' such as pointing and using words are important here but the actual act of solving the puzzle is not verbal but a direct vision that occurs out of the tension created by the two different suggestions. This is not a mechanical solution but a creative leap in which Elaine takes on the position of 'witness' or superaddressee.

\section{Example 2: Commutativity}

This next example has a very similar structure but it is more obviously applied to conceptual development in arithmentic. Mathematics education expert Carol Murphy and I, with other colleagues at the University of Exeter, put together a project combining Exploratory Talk (or Dialogic Talk) and mathematics to see if talking together would help young children shift up a level in their understanding of mathematics concepts. We are only halfway through analysing the results of the project but the results so far look promising.

One teacher we are working with, Susan, taught her class of 6 and 7-year-olds the ground rules for Exploratory Talk and then asked them to work together in groups of three solving a simple form of magical square. They were given the numbers 3, 2 and 1 on cards and asked to arrange them in a 3 by 3 grid so that every row and column added up to the same. 
Figure 2 Magic square

In one group we video-recorded two of the group, Jack and Amy, worked industriously arranging numbers and counting them out while a girl called Judy just watched them.

'Two, three and one' Jack counted on his fingers, 'that's six'. 'One, three and two', Amy counted on her fingers, 'six'.

They were succeeding at the task, finding the way in which the numbers could be used to make all the rows and columns add up to the same total but they did not seem to realize that 3 $+2+1$ was the same as $1+2+3$ and the same as $2+1+3$ etc. Judy sucked her finger looking on then said: 'They are all adding up to six, look they are all six'. She said it quite loud and they certainly heard her but they carried on counting them out numbers in rows and columns as if they had not really understood her point.

When Susan the teacher came around to this group she praised them for arranging the numbers correctly to form a magic square and emphasized the point that Judy had seen, that if you use only the three number cards ' 1 ', ' 2 ' and ' 3 ' then the answer is always 6 regardless of the order. She concluded by saying, 'So, there is no need to keep counting on your fingers, you know that they add up to six'.

This group had not been using all the talk ground rules but the collaboration itself seemed to spark an insight in Judy and prepared the ground for teaching the concept of commutitivity: that $1+2$ is the same as $2+1$ etc. It is interesting that out of the three children Judy was the one least involved in the procedure of the task but was the one looking on. There is an old saying 'Two is company, three's a crowd'. In groups of three two children will often happily support each other in doing the task as they see it while one is left out slightly. This knowledge that three is an awkward number often leads teachers to be resistant to the idea of grouping in threes. But the experience of the Thinking Together project shows that three is the best number for developing thinking. The child left feeling a bit spare in the group is often the one who challenges the others to think more about what they are doing. 


\section{Example 3: Invoking the absent addressee}

Above we described how thinking is called forth by the superaddressee or witness. The crucial role that the absent addressee can play in precipitating a shift in understanding can be seen clearly in some data from an American primary classroom.

In the data a group of four children had been told to make a graph but had not been told how to make it. They had been growing plants as a class and had measured each plant's height each day. One of the children, Angelina, wanted to write down all the observation data in cells linked to each plant name. She had not really understood how a graph can help display information. Julia and Tom argued with her that they should map the height of the plants on one axis against the days on the other axis. They argued for a long time even turning the graph paper around so that they could literally see it from each other's point of view. At one point in the video it is possible to see that Angelina changes her mind quite dramatically and concedes to the argument of the others. How does this happen? She precedes her change of mind by listening intently to Julia then turning her head away from Julia a little, as if for a moment of private thought, then she lifts her head slowly with a long drawn out 'Ohhh!' her eyes widen as her mouth opens into the ' $\mathrm{O}$ ' shape which is at the same time a kind of smile.

Is it the argument that Julia has just given that enables her to see things so differently? Before Angelina's conversion, Will had just said:

'That's what you're telling them with the graph - that's why we're making the graph!'

And then Julia had added:

'We're saying: "It's day nineteen - how is it going?"

As she said this she turned a little to the side and made an exaggerated welcoming gesture with her hand drawing in an imaginary viewer from outside to look at the graph.

There was something at stake for Angelina in not changing her mind as she had invested time in her arguments and she wanted to be right, yet she found herself led, almost despite herself, to see Julia's point of view. The quality of the relationships in the group is crucial to this achievement of unforced agreement. The ground rules operating in this group meant that challenges were responded to with reasons, not with a breakdown of communication, and that changes of mind were possible (although this was touch and go at times as they got quite angry with each other). 
It seems that Angelina's change of mind here did not stem from any abstract logic so much as from a shift in perspective to see the graph from a projected future point of view - the point of view of the future viewer of the graph referred to and brought into the discussion by Julia and Will. This change of mind is preceded by the gesture of drawing in the alternative perspective, the future viewer.

\section{Discussion: Towards a dialogic theory of learning to think}

My argument in this paper is that conceptual development is not about experience being drawn up into a pre-existing logical system or conceptual system or system of words (Vygotsky, 1981: Wertsch and Kazak, 2011) but about experience being organized by seeing as if from the perspective of others, both real others and virtual others. I have proposed a developmental sequence in learning to think well from responding to the call of real voices, to responding to the call of absent cultural voices, such as the projected future reader of a text or the Generalised Other of Mead, on to a relationship with the Infinite Other which is not a position so much as a process of questioning and a call to go beyond existing images. In the first two examples of talk in classrooms we saw children being moved on conceptually by seeing as if from the witness position whereas in the third the conceptual shift was triggered by invoking the perspective of an absent future addressee. Since each virtual witness and absent addressee can themselves be questioned generating a new superaddressee position this feature of dialogues is a source of an infinite creative potential for seeing things in new ways.

It might be argued that the concept of dialogic is not very useful because in fact everything is dialogic. The structure of consciousness itself is dialogic, if consciousness can be understood as seeing as if through others eyes. There is always more than one perspective or more than one voice in play so the idea of monologic is an illusion. This is all true but if monologic, which is the ideal of there being only one true representation, is an illusion then it is a very influential illusion. In lived reality we experience a continuum between more monologic voices and more dialogic voices. The sign that says 'no walking on the grass' is a more monologic kind of voice than a friend who explains to me that his grass needs time to grow and so asks me please not to walk on it today. The first is an outside voice of authority, the second a persuasive voice that enters into my world as if the words were my own words (Bakhtin, 1986). Similarly some people seem to be more monologic than others. Experience in classrooms suggests that this is probably not due to any fixed character traits but to sociocultural identifications that can be changed through education. Some shout their views and 
refuse to listen displaying an intersubjetive orientation that Mercer called 'disputational' (Mercer, 1995). Others may be more quiet but they agree with 'what everyone says' and ignore any challenges to this groupthink. Such people display the orientation the Mercer called cumulative, again in the context of groups talking together in primary classrooms (Mercer, 1995). These are two ways of not thinking well because blocked by monologic identifications. In each case strong identification with a limited image, a self image in one case and a group image in the other, prevents the openness to the question which is necessary for good thinking. Teaching thinking therefore means, amongst other things, drawing learners away from over-identification with closed and limited identities (monologics) and to open them up to questioning from other perspectives (dialogic). Doing this is moving them on a scale from monologism towards dialogism: from identifying with a closed image towards identifying with the infinite openness and potential of the process of dialogue itself.

\section{Conclusions}

The examples I gave of thinking breakthroughs in primary classrooms illustrated some intersubjective mechanisms for taking thought further. In the first two examples teaching ground rules that opened a space of reflection enabled children to step back from each other's ideas and leapfrog them into new insights that combined the ideas of others into a new vision. In the third example the children spontaneously invoked the perspective of the absent future addressee in order to make sense of what they were doing a prompt a breakthrough in understanding. Although each new vision can be partially reified into a concept, a clearly defined mathematical concept such as 'cummutitivity' in the second example, in fact each new concept is also a kind of dialogue that brings different perspectives and different experiences together dynamically to talk to each other. Concepts, it turns out, instead of closing things down can open up new perspectives as if starting points for a new dialogues with new potentials for meaning (Linell, 2009). Cognitive development, which has often been described in monologic terms, can therefore be re-conceptualised in a more dialogic way as drawing isolated moments of experience up into larger dialogues. This is the development that Bakhtin wrote of when he implicitly talked of moving from the 'narrow time' of the here and now, towards that 'Great Time' in which every voice is in dialogue with every other voice (Bakhtin, 1986). At the same time this model of teaching and learning thinking has useful implications for classroom practice. It suggests teaching children how to question each 
other and how to constantly invoke the voice of absent witnesses in order to help make sense of what they are doing and to grow in insight (Wegerif, 2010 gives many more practical illustrations of this approach to teaching thinking).

The idea of dialogic is not limited to dialogue with this or that image of a specific 'other' person but can lead us beyond the particular other person into dialogue with infinite otherness: that otherness that always outstrips us and that never allows us to say 'now I know the truth so I can stop thinking'. Teaching thinking is drawing learners through relationships into a state of being more at home in openness and multiplicity. Learning to think on this model can therefore be seen as a trajectory of identification from initial identification with closed images of self and group towards an identification with the radical openness of dialogue itself. According to this dialogic theory of learning to think: to learn to think is to become dialogue with others; to learn to think well is to become dialogue with the Infinite Other.

When Bruner claimed that everyone was either following Piaget or Vygotsky or adopting a position between the two (Bruner, 1996) he was assuming that the key distinction in theories of cognitive development was that between a focus on individual mechanisms (mostly neoPiagetian) as opposed to a focus on social mechanisms (mostly neo-Vygotskian). In this paper I have argued by contrast that the key distinction is between monological theories and dialogical theories. Piaget and Vygotsky offered different monological theories of development. Using the stimulus of Bakhtin's notion of the superaddressee I have tried to show that a genuinely dialogic alternative account of cognitive development or 'how children learn to think', is possible. Because this account is not about cognition in the abstract but about thinking as an aspect of relationships in context it potentially fits better than either Piaget or Vygotsky with the new insights that are emerging from research on the brain (e.g Damasio, 1994 and Gallagher, in press).

This paper offers more of a sketch towards a possible theory than a fully elaborated theory. The account of how changing identifications in dialogue towards identification with dialogue itself can lead to improved thinking has good empirical support (Wegerif and Mercer, 1998: Wegerif et al, 2005). The philosophical argument that learning to think involves responding to the call of others and of the Infinite Other is plausible as an extension of arguments already widely accepted after their initial articulation by George Herbert Mead (Mead, 1934). However this paper is perhaps on weaker ground with the third leg of the argument, which is 
an account of learning as a trajectory of identity towards identification with dialogue as an end in itself. Changing identifications are certainly an important aspect of learning but there are other aspects that could equally have been focussed upon. In terms of the two metaphors of learning that Anna Sfard (1999) discusses, learning as a trajectory of identification only makes use of one metaphor, the metaphor of 'learning as participation' while the other equally important metaphor of 'learning as acquisition' is not adequately addressed. This suggests a need for further detailed research exploring how individual skills and dispositions change through engagement in different kinds of dialogue and exactly how individual brains change and develop through self-identification with different kinds of dialogue.

${ }^{1}$ The data was from the work of Richard Lehrer and Leona Schnauble to whom much thanks.

\section{References}

Anderson, J. R. (1983) The Architecture of Cognition, Cambridge, MA: Harvard University Press.

Badiou, A (1988) Being and Event. London: Continuum.

Bakhtin, M. (1981). Discourse in the Novel. In M. M. Bakhtin. The dialogic Imagination. Four essays by M. M. Bakhtin. Austin: University of Texas Press.

Bakhtin, M. (1986) Speech Genres and other Late Essays. Austin:University of Texas.

Biesta, G. (2006) Beyond Learning: Democratic Education for a Human Future. Boulder CO: Paradigm Press.

Boden, M. A. (1990). The creative mind. Basic Books: New York.

Buber, M. (1958) I and Thou (2nd edn, trans. R. Gregory Smith), Edinburgh: T. and

Clark, H. H., and Brennan, S. A. (1991). Grounding in communication. In L.B. Resnick, J.M. Levine, \& S.D. Teasley (Eds.). Perspectives on socially shared cognition . Washington: APA Books.

Cobb, P., Gresalfi, M., and Hodge, L. L. (2009). An interpretive scheme for analyzing the identities that students develop in mathematics classrooms. Journal for Research in Mathematics Education, 40, 40-68.

Damasio, A.R. (1994) Damasio, Descartes' Error: Emotion, Reason, and the Human Brain, Putnam, New York

Dawes, L. Mercer, N., and Wegerif, R (2000), Thinking Together: Activities for Key Stage 2 children and teachers. London: Questions Publishing. 
Ed.: Morris, M \& Parkinson, G., Trans.) London: Dent and Sons.

Gallagher, S. (in press). Neurons, neonates and narrative: From embodied resonance to empathic understanding. In Ad Foolen, Ulrike Lüdtke, Jordan Zlatev and Tim Racine (eds.), Moving Ourselves: Bodily motion and emotion in the making of intersubjectivity and consciousness. Amsterdam: John Benjamins.

Heidegger, M. (1978) Basic Writings. London, Routledge

Lave, J., \& Wenger, E. (1991). Situated Learning: Legitimate Periperal Participation. Cambridge, UK: Cambridge University Press.

Leibniz, G. (1973). Leibniz: Philosophical Writings (Parkinson, G.

Lévinas, E. (1978) Autrement qu'être ou au-dela de l'essence. Paris: Livre de poche

Linell, P. (2009). Rethinking Language, Mind and World Dialogically: Interactional and contextual theories of human sense-making. Charlotte, NC: Information Age Publishing.

Matusov, E. (2009)._Journey into dialogic pedagogy. Hauppauge, NY: Nova Publishers.

Matusov, E. (2011). Irreconcilable differences in Vygotsky's and Bakhtin's approaches to the social and the individual: An educational perspective. Culture \& Psychology, 17 (1), 99-119.

Mead, G H (1934). Mind, Self, and Society. (Ed. by Charles W. Morris.) Chicago: University of Chicago Press.

Mercer, N. (1995) The Guided Construction of Knowledge: talk amongst teachers and learners. Clevedon: Multilingual Matters.

Mercer, N. \& Littleton, K. (2007) Dialogue and the Development of Children's Thinking: a sociocultural approach. London: Routledge

Merleau-Ponty, M. (1964). Le Visible et L'Invisible. Paris: Gallimard.

Merleau-Ponty, M. (1968). The Visible and the Invisible (Edited by Claude Lefort and translated by Alphonso Lingis). Evanston, II: Northwestern University Press.

New Testament ( 50) Available online at http://www.devotions.net/bible/00new.htm . (Accessed on 18th June 2011.)

Plato, (450 BCE) The Phaedrus. Translated by Benjamin Jowett. Online. Available http://ebooks.adelaide.edu.au/p/plato/p71phs/phaedrus.html (accessed 1st August 2008)

Rogoff, B. Gauvain, G. \& Ellis, C. (1991). Development viewed in its cultural context. In P. Light, A. Sheldon and B. Woodhead (Ed.) Learning to think. London: Routledge/OU.

Rojas, S., Drummond, M., Fernandez, N., Mazon, R. \& Wegerif, R. (2006). ... Thinking Skills and Creativity 1(2), 84-94.

Rommetveit, R. (1992). Outlines of a dialogically based social-cognitive approach to human cognition and communication. In A. Wold (Ed.). The dialogical alternative: towards a theory of language and mind (pp. 19-45). Oslo: Scandanavian Press. 
Sfard, A. (1998). On two metaphors for learning and the dangers of choosing just one. Educational Researcher, 27(2), pp. 4-13

Sharples, M. (1999). How we write: an account of writing as creative design. Routledge, London.

Sidorkin, A. M. (1999). Beyond discourse: Education, the self and dialogue. New York: State University of New York Press.

Van der Veer, R. \& Valsiner, J. (1991). Understanding Vygotsky: a quest for synthesis. Oxford: Blackwells.

Volosinov, V. N. (1986). Marxism and the philosophy of language. Cambridge, MA: Harvard University Press.

Vygotsky, L. (1986) Thought and Language. (Translated by A. Kozulin) Cambridge Ma.: MIT Press

Wegerif, R (2007) Dialogic Education and Technology: expanding the space of learning,

Wegerif, R. (1999) Two models of reason in education. The School Field. 9 (3-4): 77-107

Wegerif, R. (2004). Towards an Account of Teaching General Thinking Skills That is Compatible with the Assumptions of Sociocultural Theory. Theory and Research in Education 2(2), 143-159.

Wegerif, R. (2005) 'Reason and creativity in classroom dialogues', Language and

Wegerif, R. (2010) Mindexpanding: Teaching for thinking and creativity in primary education. Buckingham: Open-University Press

Wegerif, R. (2011). From Dialectic to Dialogic: A response to Wertsch and Kazak. In T. Koschmann (Ed.), Theories of Learning and Studies of Instructional practice. New Jersey: Springer.

Wegerif, R. and Dawes, L. (2004) Thinking and Learning with ICT: raising achievement

Wegerif, R. and Mercer, N. (1997) A Dialogical Framework for Investigating Talk. In Wegerif, R. and Scrimshaw, P. (Eds) Computers and Talk in the Primary Classroom, pp 49-65. Clevedon: Multilingual Matters. ISBN: 1853593915

Wegerif, R. Mercer, N. \& Dawes, L. (1999). From social interaction to individual reasoning: an empirical investigation of a possible sociocultural model of cognitive development. Learning and Instruction. 9(5). 493-516

Wegerif, R. Perez Linares, J. Rojas Drummond, S. Mercer, N. Velez, M (2005). Thinking Together in the UK and Mexico: transfer of an educational innovation. Journal of Classroom Interaction, 40(1). 40-47.

Wells, G. (1999). Dialogic Inquiry: Towards a Sociocultural Practice and Theory of Education. Cambridge: Cambridge University Press.

Wenger, E. (1999) Communities of Practice. Learning, meaning and identity, Cambridge: Cambridge University Press

Wertsch, J and Kazak, S. (2011) Saying more than you know in instructional Settings. In T. Koschmann (Ed.), Theories of Learning and Studies of Instructional practice. New Jersey: Springer. 
Wertsch, J. (1996). The role of abstract rationality in Vygotsky's image of mind. In A. Tryphon \& J. Voneche (Eds.), Piaget - Vygotsky: The Social Genesis of Thought, Hove:

Psychology Press. 